OPEN ACCESS

Edited by:

Alberto Camacho-Morales,

Autonomous University of Nuevo

León, Mexico

Reviewed by:

Claudia Cristiano,

University of Naples Federico II, Italy

Dario Siniscalco,

University of Campania Luigi Vanvitelli,

Italy

${ }^{*}$ Correspondence: Li Zhang

zhangli@jnu.edu.cn

Specialty section:

This article was submitted to

Cellular Neuropathology,

a section of the journal

Frontiers in Cellular Neuroscience

Received: 11 November 2019

Accepted: 12 March 2020

Published: 31 March 2020

Citation:

Qi X-R and Zhang L (2020) The

Potential Role of Gut Peptide

Hormones in Autism Spectrum

Disorder. Front. Cell. Neurosci. 14:73

doi: $10.3389 /$ fncel.2020.00073

\section{The Potential Role of Gut Peptide Hormones in Autism Spectrum Disorder}

\author{
Xin-Rui Qi' and Li Zhang ${ }^{2 *}$ \\ ' Center for Translational Neurodegeneration and Regenerative Therapy, Shanghai Tenth People's Hospital Affiliated to Tongji \\ University School of Medicine, Shanghai, China, ${ }^{2}$ Joint International Research Laboratory of CNS Regeneration, \\ Guangdong-Hong Kong-Macau Institute of CNS Regeneration, Jinan University, Guangzhou, China
}

Gut peptide hormones are one group of secretory factors produced from gastrointestinal endocrine cells with potent functions in modulating digestive functions. In recent decades, they have been found across different brain regions, many of which are involved in autism-related social, emotional and cognitive deficits. Clinical studies have revealed possible correlation between those hormones and autism spectrum disorder pathogenesis. In animal models, gut peptide hormones modulate neurodevelopment, synaptic transmission and neural plasticity, explaining their behavioral relevance. This review article will summarize major findings from both clinical and basic research showing the role of gut peptide hormones in mediating autism-related neurological functions, and their potential implications in autism pathogenesis. The pharmaceutical value of gut hormones in alleviating autism-associated behavioral syndromes will be discussed to provide new insights for future drug development.

\footnotetext{
Keywords: autism, cholecystokinin, ghrelin, gut peptide hormone, pituitary adenylate cyclase activating peptide, secretin, vasoactive intestinal peptide
}

\section{INTRODUCTION}

Autism spectrum disorder (ASD) affects more than 1.5\% of children worldwide (Christensen et al., 2016). It is estimated that genetic factors contribute to about $60 \%$ of ASD cases (Tick et al., 2016) although there are still episodic cases that cannot be fully explained by hereditary factors. Emerging evidence is suggesting gut dysfunctions in ASD, which is frequently correlated with digestive disorders. Typical gastrointestinal (GI) symptoms associated with ASD include abdominal pain, flatulence, indigestion or diarrhea (Adams et al., 2011), whose incidence were as higher as $70 \%$ in ASD children (Li and Zhou, 2016).

Gut peptide hormones refer to a group of polypeptides derived from GI tract and can exert multiple physiological functions via binding with specific receptors. Gut peptides have a long history since the identification of its first member, secretin, at almost 100 years ago. Currently dozens of molecules have been classified into this group, including cholecystokinin (CCK), 
vasoactive intestinal peptide (VIP), pituitary adenylate cyclase activating peptide (PACAP), peptide YY (PYY), secretin, pancreatic polypeptide, ghrelin and so on (Small and Bloom, 2004; Wren and Bloom, 2007; Neary and Batterham, 2009). Those secretory factors have been recognized for their roles in modulating GI functions and body energy metabolism. In recent $20 \sim 30$ years, their brain functions are being gradually revealed from molecular, behavioral and physiological evidence (Zhang and Chow, 2014; Donahue et al., 2016; Kingsbury and Wilson, 2016). For example, CCK and VIP are now working as markers for specific sub-population of neurons having unique morphological features of axon collaterals and firing patterns (Kawaguchi and Kondo, 2002). On the other hand, gut peptides also directly participate in the regulation of neural functions across different brain regions. Among those neurological effects, people are more familiar with the central appetite control in which gut peptides can sense the satiety and energy requirement, and mediate the activity of central feeding nuclei within arcuate nucleus (Arc) of the hypothalamus and the nucleus of the solitary tract (NTS) via vagal afferent pathway or direct effects on central nuclei (Konturek et al., 2004; Small and Bloom, 2004; Wren and Bloom, 2007; Troke et al., 2014; Roman et al., 2017).

Besides the feeding and metabolic regulation, the potential role of gut peptide hormones in other behavioral paradigms is emerging in recent decades. Notably, some gut peptides are involved in social functions. Examples include secretin, whose gene knockout in mice leads to social interaction deficits (Nishijima et al., 2006), and VIP with potent functions for social affiliation and aggression (Kingsbury and Wilson, 2016). As social deficit is one of core symptoms of ASD, one may speculate that gut peptides are related with ASD pathogenesis. Therefore, further understandings of gut peptide hormones in ASD should help to better elucidate both pathogenic mechanism and to develop potential intervention strategy of ASD.

In this mini review, for each gut peptide hormone we will start with its distribution and functions in the central nervous system, following with the evidence of its involvement in ASD. We will also discuss about the neurobiological mechanisms of those gutbrain peptides, with particular interests in mediating social and cognitive deficits as well as stereotypic behaviors, all of which are the core behavioral symptoms of ASD. Lastly, the potency of drug development targeting those gut peptides and their receptors in alleviating ASD-related symptoms will be discussed.

\section{GUT PEPTIDE HORMONES AND ASD}

Gut peptide hormones exert various neuromodulating effects as suggested by their wide distribution across different brain regions. Recent advances in neural science techniques including gene knockdown, in vivo recording, opto-/chemo-genetics have made it possible to delineate specific functions of those peptides within certain neural circuits including those related with ASD.

\section{CCK}

As one widely studied gut-brain peptide, CCK can be found within a certain group of inhibitory neurons and has known effects in mediating appetite and food intake (Degen et al., 2001). Previous studies have found that social isolation increases CCK mRNA expression in amygdala, hippocampus, cortex and ventral tegmental area (VTA) nuclei of rats (Del Bel and Guimaraes, 1997). Clinical assays also showed that decreased serum CCK-8 (Brambilla et al., 1997) is found in ASD children. Furthermore, in patients with Asperger's syndrome (AS), a subgroup of autistic patients, one fragment deletion has been found in CCK gene (Iourov et al., 2015). Those animal and clinical data thus suggest the possible linkage between CCK and ASD.

Some studies have already been done to investigate the potential neurological mechanisms of CCK in social behaviors. Targeted mutation of CCK receptor alters social isolationrelated behaviors in female mice (Abramov et al., 2004). The selective activation of CCK-neurons (Whissell et al., 2019) and selective modulation of CCK receptors (Lemaire et al., 1992) enhances social recognition or social memory. At the upstream of CCK, endocannabinoid system plays a critical role. In hippocampal nuclei, endogenous cannabinoid receptor 1 (CB1R) suppresses CCK-positive neurons, leading to altered social behaviors (Vargish et al., 2017). Further analysis showed that CB1 modulated CCK transmission to direct social withdraw behaviors (Seillier et al., 2013). A recent study also found that CB1R in the amygdala CCK-positive afferents to nucleus accumbens modulates social defeat-induced depressive behaviors (Shen et al., 2019). The inter-correlation between endocannabinoid and CCK system may reside in the co-expression of CB1R and CCK in certain groups of interneurons (Rovira-Esteban et al., 2017). In future, more studies can be performed to elucidate the neural circuit of CCK in mediating social behaviors.

\section{PACAP}

PACAP is one polypeptide hormone sharing high sequence similarity with secretin and is also involved in social modulation. Genetic study investigated more than 1,000 ASD children with their normal siblings and identified one specific loci (rs1557299) at the downstream of PACAP gene (Nijmeijer et al., 2010) which suggested close relationship between PACAP and ASD. Furthermore, animal studies showed that PACAP is an important gut peptide in modulating social and emotional behaviors. For example, the intracerebroventricular infusion of PACAP into rat brains leads to the decrease of social behaviors (Donahue et al., 2016). On the other hand, PACAP - deficient mice presented the attenuation of depressive disorders after chronic social defeat stress (Lehmann et al., 2013). However, the knockout of PACAP type 1 receptor (PAC1) in male mice decreased social investigations after repeated exposure to the same subject, in conjunction with excessive sexual mounting and lower aggressive behaviors (Nicot et al., 2004). Those seemingly contradictory phenotypes suggest the homeostatic regulation of PACAP in maintaining normal social behaviors. The administration of PACAP also leads to prominently enhanced locomotor activity plus rearing behaviors in mice (Masuo et al., 1995; Norrholm et al., 2005), and the deficiency of PACAP in mice results in hyperactivity and jumping behaviors in a novel field (Hashimoto et al., 2001). Therefore, PACAP mediates various behavioral phenotypes that can be related with ASD. 
Electrophysiological studies reveal that PACAP improves synaptic plasticity in mouse hippocampus (Cabezas-Llobet et al., 2018), and increases both frequency and amplitude of excitatory postsynaptic currents (EPSCs) of autonomic synapse (Starr and Margiotta, 2017), giving clues of how PACAP is involved in the autism-related behaviors. In addition, studies are gradually revealing the modulatory function of PACAP in neurodevelopment and neuroprotection, which might give further explanation for its involvement in ASD, which is one neurodevelopmental disorder. As further evidence, PACAP can stimulate the growth of both axons (Ogata et al., 2015) and dendritic spines (Cabezas-Llobet et al., 2018) under normal or disease conditions. Moreover, PACAP receptor PAC1 also mediates the differentiation and migration of cortical neuronal progenitors (Adnani et al., 2015).

\section{VIP}

VIP is mainly expressed in the hypothalamic nuclei such as suprachiasmatic nucleus (SCN) and tuberal hypothalamus as well as hippocampus and cerebral cortex (Acsady et al., 1996a,b), and is now commonly accepted as a neuroendocrine hormone, putative neurotransmitter and cytokine. Its biological effects are mediated by binding to the G-protein coupled receptors (GPCRs), VPAC1 and VPAC2, which have high affinity to VIP (Iourov et al., 2015). Previously, it has been shown to stimulate prolactin secretion from the pituitary (Reichlin, 1988) and catecholamine release from the adrenal medulla (Malhotra et al., 1988). It also participates in non-adrenergic, non-cholinergic relaxation of both vascular and non-vascular smooth muscle as co-transmitters with nitric oxide and carbon monoxide (Said and Rattan, 2004).

Recent evidence suggested a close relationship between VIP and ASD. Newborns with higher VIP concentrations in the cord blood were more likely to develop autism in later periods (Nelson et al., 2001). Preliminary evidence has showed that ASD phenotype is associated with VPAC2 receptor duplication (Levinson et al., 2011). The involvement of this duplication in ASD is further confirmed by a recent report observing such copy number variants in autistic child and his father with a mild autism (Firouzabadi et al., 2017). Preclinical studies support the roles of VIP in social and cognitive functions. After VIP antagonist treatment during the embryonic stage, male offspring exhibited reduced sociability and deficits in cognitive function, as assessed through cued and contextual fear conditioning (Hill et al., 2007). Male offspring of pregnant females with VIP deficiency also exhibited deficits in social approach behavior and reversal learning, with more severe and higher prevalence compared to their female littermates (Lim et al., 2008; Stack et al., 2008). VIP-deficient mice exhibited a pronounced reduction in social recall when tested 48 -h or longer after primary training (Chaudhury et al., 2008). On the other hand, some early studies showed that the intracerebroventricular administration of VIP also caused a marked impairment in passive avoidance and spatial memory, together with neuronal dystrophy (Takashima et al., 1993a,b). As further supporting evidence, VIP can stimulate neurogenesis as well as cell differentiation to promote neuronal survival and regeneration probably via the induction of nerve growth factor and activity dependent neuroprotective protein (Hill et al., 2002; Giladi et al., 2007). In addition, VIP has been observed to modulate synaptic transmission efficiency via the regulation of brain-derived neurotrophic factor (BDNF) expression in cortical neurons (Pellegri et al., 1998; Ciranna and Cavallaro, 2003), providing possible mechanism for behavioral modulation.

\section{Ghrelin}

Ghrelin, a 28-amino-acid peptide hormone, is mainly produced by gastric oxyntic cells. In the central nervous system, ghrelin has been detected in the hypothalamus such as Arc, ventromedial and paraventricular nucleus areas (PVN) (Kojima et al., 1999; Lu et al., 2002; Hori et al., 2008). The hypothalamic roles of ghrelin consist of appetited regulation, glucose homeostasis, and growth hormone release from pituitary and body weight regulation (Kojima and Kangawa, 2005). Furthermore, ghrelin is found in extra-hypothalamic areas such as hippocampus, sensorymotor cortex and cingulate cortex which might be involved in higher cognitive functions (Hou et al., 2006). Ghrelin is present in two major forms: un-acylated ghrelin (des-acyl ghrelin or DAG) and acylated ghrelin (AG, C-ghrelin, or also referred to as ghrelin) which was produced by ghrelin $\mathrm{O}$-a-cyl-transferase (GOAT) from DAG. Only AG is able to bind to the growth hormone secretagogue receptor type 1 a (GHSR1a), a G proteincoupled receptor, to execute their biological functions (Kojima et al., 1999, 2001). GHSR1a is widely distributed in the brain such as in the hypothalamus, hippocampus, substantia nigra, VTA and several thalamic and brain stem nuclei (Guan et al., 1997). Those expressional data indicate the potential neural function of ghrelin.

Recent study revealed the close relationship between ghrelin and ASD. For example, the expression level of un-acylated ghrelin acylated ghrelin in blood is lower in children with autism (Al-Zaid et al., 2014). Ghrelin has also been postulated to be one promising target in co-morbid between autism and epilepsy (Ghanizadeh, 2011). Animal studies show that ghrelin plays important roles in learning and memory, sleep and appetite, all of which are disturbed in ASD. Intracerebroventricular or intra-hippocampal injection of ghrelin increased memory acquisition and/or consolidation, but not in memory retrieval (Carlini et al., 2002, 2010). Ghrelin-knockout mice exhibited decreased hippocampal spine density and abnormal memory that can be reversed by ghrelin injection (Diano et al., 2006). In addition, GHSR1a knockout mice showed a decreased food intake after three days on restricted feeding schedule and failed to show preference to rewarding high-fat diet food (Abizaid et al., 2006), suggesting the role of ghrelin in reward circuitry modulation. In physiological terms, ghrelin was found to enhance synaptic plasticity by increasing spine formation and long term potentiation (LTP), to promote neurogenesis (Zhang et al., 2004; Moon et al., 2009), to preserve mitochondrial integrity, and to inhibit the apoptotic process and neuronal cell death (Chung et al., 2007; Lee et al., 2010). Moreover, ghrelin was recently reported to reduce mRNA expression of tumor necrosis factor- $\alpha$ (TNF$\alpha$ ) and nuclear factor kappa $B(N F-\kappa B)$ in lymphoblastoid 
cell lines from ASD subjects (Yamashita et al., 2019), suggesting the possible involvement of neuroinflammatory modulation of ghrelin.

\section{Secretin}

Secretin is one classical gut-peptide hormone to modulate pancreatic secretion as well as body energy homeostasis. Several lines of evidence from rodent and human studies show that secretin and its receptors are widely distributed in the brain areas from cerebral cortex, hippocampus, amygdala, hypothalamus to cerebellum (Yuan et al., 2011; Wang et al., 2019). The neurological functions of secretin are also being gradually explored by molecular, physiological and behavioral approaches (Zhang and Chow, 2014; Wang et al., 2019).

In 1998, a case series reported secretin in amelioration of the symptoms in three ASD children (Horvath et al., 1998). However, later double-blind placebo-controlled clinical studies revealed that there was a lack of significant impact of secretin in the treatment of ASD symptoms (Esch and Carr, 2004; Malone et al., 2005; Krishnaswami et al., 2011; Lyra et al., 2017). In spite of the failure in clinical studies, animal obervations support the roles of secretin in some social functions. For example, secretin receptor deficient mice presented impaired social interaction (Nishijima et al., 2006), and one later study revealed the potentiation of social recognition by secretin infusion via the activation of oxytocin pathway (Takayanagi et al., 2017). One possible mechanism exists as secretin increases the release of vasopressin (Chu et al., 2009) which can regulate social behaviors (Dumais and Veenema, 2016). Besides social regulation, in a mutant mouse model with stereotypically circling locomotion, secretin infusion effectively attenuated those abnormalities (Koves et al., 2011). Altogether, these data might indicate an indirect roles played by secretin in the ASD pathogenesis and treatment.

For investigating the molecular and cellular mechanism, secretin has been found to induce the spinogenesis of hippocampal neurons (Nishijima et al., 2006), and the deficiency of secretin impairs both the induction and maintenance of LTP in hippocampal neurons (Yamagata et al., 2008). We recently found that secretin could potentiate postnatal proliferation and migration of cerebellar granular neurons (Wang et al., 2017) and potentiate inhibitory postsynaptic currents (IPSCs) of cerebellar Purkinje neurons (Yung et al., 2001), adding further knowledge to the neural plasticity modulation by secretin. As the secretin receptors mostly belong to GPCR family, the activation of cyclic AMP (cAMP)-protein kinase A (PKA) pathway in brain regions have been established for secretin (Pang et al., 2015). This also holds true for VIP and PACAP, which have high degree of sequence similarity with secretin (Jozwiak-Bebenista et al., 2015). The activation of cAMP-PKA pathway exerts pluripotent functions, among which the modulation of ion channels or neurotransmitters directly affects synaptic transmission (Wang et al., 2019). Alternatively, other downstream pathways such as cAMP-response element - binding protein (CREB) activation (Mak et al., 2019) can initiate the translation of synaptic proteins to modulate long-term plasticity and memory functions. The extracellular signal regulated kinase (ERK) pathway is also involved upon secretin stimulation (Wang et al., 2017). In sum, secretin is one possible modulator of social functions, and is worth further investigation to reveal detailed circuitry effects.

\section{IMPLICATIONS FOR AUTISM DRUG DEVELOPMENT}

Based on the inter-correlation between ASD pathogenesis and potentially neurological mechanisms in regulating social, emotional and repetitive behaviors by gut peptides, it is expected that those hormones may work as drug candidate or targets for developing novel drugs in alleviating ASD symptoms. However, failures are frequently reported when directly trying the administration of those peptides to ameliorate autistic behaviors. For example, one clinical trial failed to detect significantly improvement of social phobia by using CCK-tetrapeptide (CCK4) (Katzman et al., 2004), and many double-blind placebocontrolled studies using secretin to alleviate autism symptoms infusion have also been failed (Esch and Carr, 2004; Malone et al., 2005; Krishnaswami et al., 2011; Lyra et al., 2017) even though the existence of one early study reporting the beneficial effects of secretin (Horvath et al., 1998). Therefore, major challenges are faced by those gut hormones probably due to their rapid turnover in vivo and low efficiency for penetrating the blood brain barrier $(\mathrm{BBB})$. Large amounts of works are thus required to overcome those disadvantages and to generate drug candidates with satisfactory efficiency, persistency and safety.

The short half-life is one common property of gut hormones due to their peptide composition. For example, secretin has less than 5 min half-life under normal physiological conditions (Kolts and McGuigan, 1977), making it impossible to achieve stable drug concentration in vivo. Such limitation can be addressed by two approaches: the development of stable analog or receptor agonist, or the application of bioengineered sustained drug delivery system. The former approach is based on molecular design and screening of small molecules, or the modification of existing receptor ligands, to generate long-lasting effects as those of natural ligands. Alternatively, one can adopt nanoparticles system to chronically release peptide drugs such as those used in immunomodulation therapy for releasing autoantigens (Stabler et al., 2019). In drug development, the issue of BBB permeability should also be considered case-by-case. Current knowledge agree that VIP, secretin and PACAP27 can be transported into the brain by a non-saturable mechanism, or transmembrane diffusion, whilst PACAP38 and gastric inhibitory polypeptide (GIP) have no known routes in enter the central nervous system (DogrukolAk et al., 2004). Those data thus suggest that it is necessary to develop new drug delivery system to penetrate the BBB and to chronically release effective gut peptide hormones.

\section{CONCLUSION}

Gut peptide hormones are now recognized as having prominent brain distributions and various behavioral modulatory functions. Clinical studies with ASD subjects have revealed that the 
genetic polymorphisms of gut peptides such as CCK, PACAP, and VIP are related to ASD. Altered expression levels of the peptides including CCK and ghrelin are found in ASD children. Additionally, more animal studies suggest that these gut peptides are actively involved in the modulation of social, emotional and stereotypic behaviors. In future, one should perform more site-specific studies to illustrate the precise mechanisms of gut peptides in mediating social or emotional or cognitive behaviors for potential drug targets. Further drug development can be pursued to generate stable analogs that can modulate gut peptide pathways in the brain, aiming to relieve behavioral symptoms of ASD.

\section{REFERENCES}

Abizaid, A., Liu, Z. W., Andrews, Z. B., Shanabrough, M., Borok, E., Elsworth, J. D., et al. (2006). Ghrelin modulates the activity and synaptic input organization of midbrain dopamine neurons while promoting appetite. J. Clin. Invest. 116, 3229-3239. doi: 10.1172/jci29867

Abramov, U., Raud, S., Koks, S., Innos, J., Kurrikoff, K., Matsui, T., et al. (2004). Targeted mutation of CCK(2) receptor gene antagonises behavioural changes induced by social isolation in female, but not in male mice. Behav. Brain Res. 155, 1-11. doi: 10.1016/j.bbr.2004.03.027

Acsady, L., Arabadzisz, D., and Freund, T. F. (1996a). Correlated morphological and neurochemical features identify different subsets of vasoactive intestinal polypeptide-immunoreactive interneurons in rat hippocampus. Neuroscience 73, 299-315. doi: 10.1016/0306-4522(95)00610-9

Acsady, L., Gorcs, T. J., and Freund, T. F. (1996b). Different populations of vasoactive intestinal polypeptide-immunoreactive interneurons are specialized to control pyramidal cells or interneurons in the hippocampus. Neuroscience 73, 317-334. doi: 10.1016/0306-4522(95)00609-5

Adams, J. B., Johansen, L. J., Powell, L. D., Quig, D., and Rubin, R. A. J. B. G. (2011). Gastrointestinal flora and gastrointestinal status in children with autism - comparisons to typical children and correlation with autism severity. BMC Gastroenterol. 11:22. doi: 10.1186/1471-230X-11-22

Adnani, L., Langevin, L. M., Gautier, E., Dixit, R., Parsons, K., Li, S., et al. (2015). Zac1 regulates the differentiation and migration of neocortical neurons via Pac1. J. Neurosci. 35, 13430-13447. doi: 10.1523/JNEUROSCI.0777-15.2015

Al-Zaid, F. S., Alhader, A. A., and Al-Ayadhi, L. Y. (2014). Altered ghrelin levels in boys with autism: a novel finding associated with hormonal dysregulation. Sci. Rep. 4:6478. doi: 10.1038/srep06478

Brambilla, F., Guareschi-Cazzullo, A., Tacchini, C., Musetti, C., Panerai, A. E., and Sacerdote, P. (1997). Beta-endorphin and cholecystokinin 8 concentrations in peripheral blood mononuclear cells of autistic children. Neuropsychobiology 35 , 1-4. doi: 10.1159/000119322

Cabezas-Llobet, N., Vidal-Sancho, L., Masana, M., Fournier, A., Alberch, J., Vaudry, D., et al. (2018). Pituitary Adenylate Cyclase-Activating Polypeptide (PACAP) Enhances Hippocampal Synaptic Plasticity and Improves Memory Performance in Huntington's Disease. Mol. Neurobiol. 55, 8263-8277. doi: 10. 1007/s12035-018-0972-5

Carlini, V. P., Ghersi, M., Schioth, H. B., and de Barioglio, S. R. (2010). Ghrelin and memory: differential effects on acquisition and retrieval. Peptides 31, 1190-1193. doi: 10.1016/j.peptides.2010.02.021

Carlini, V. P., Monzon, M. E., Varas, M. M., Cragnolini, A. B., Schioth, H. B., Scimonelli, T. N., et al. (2002). Ghrelin increases anxiety-like behavior and memory retention in rats. Biochem. Biophys. Res. Commun. 299, 739-743. doi: 10.1016/s0006-291x(02)02740-7

Chaudhury, D., Loh, D. H., Dragich, J. M., Hagopian, A., and Colwell, C. S. (2008). Select cognitive deficits in vasoactive intestinal peptide deficient mice. BMC Neuroscience 9:63. doi: 10.1186/1471-2202-9-63

Christensen, D. L., Baio, J., Van Naarden Braun, K., Bilder, D., Charles, J., Constantino, J. N., et al. (2016). Prevalence and Characteristics of Autism Spectrum Disorder Among Children Aged 8 Years-Autism and Developmental Disabilities Monitoring Network, 11 Sites, United States, 2012. Morbidity and

\section{AUTHOR CONTRIBUTIONS}

X-RQ wrote the manuscript with the help from LZ. LZ revised the manuscript.

\section{FUNDING}

This study was funded by National Key Research and Development Program of China (2016YFC1306702) to LZ, and National Natural Science Foundation of China (81501172) to X-RQ.

Mortality Weekly Report. Surveillance Summaries, Vol. 65. Washington, D.C: ADDM, 1-23.

Chu, J. Y., Lee, L. T., Lai, C. H., Vaudry, H., Chan, Y. S., Yung, W. H., et al. (2009). Secretin as a neurohypophysial factor regulating body water homeostasis. Proc. Natl. Acad. Sci. U.S.A. 106, 15961-15966. doi: 10.1073/pnas.0903695106

Chung, H., Kim, E., Lee, D. H., Seo, S., Ju, S., Lee, D., et al. (2007). Ghrelin inhibits apoptosis in hypothalamic neuronal cells during oxygen-glucose deprivation. Endocrinology 148, 148-159. doi: 10.1210/en.2006-0991

Ciranna, L., and Cavallaro, S. (2003). Opposing effects by pituitary adenylate cyclase-activating polypeptide and vasoactive intestinal peptide on hippocampal synaptic transmission. Exp. Neurol. 184, 778-784. doi: 10.1016/s0014-4886(03)00300-5

Degen, L., Matzinger, D., Drewe, J., and Beglinger, C. (2001). The effect of cholecystokinin in controlling appetite and food intake in humans. Peptides 22, 1265-1269. doi: 10.1016/s0196-9781(01)00450-8

Del Bel, E. A., and Guimaraes, F. S. (1997). Social isolation increases cholecystokinin mRNA in the central nervous system of rats. Neuroreport 8 , 3597-3600. doi: 10.1097/00001756-199711100-00035

Diano, S., Farr, S. A., Benoit, S. C., McNay, E. C., da, I., Silva, B. Horvath, et al. (2006). Ghrelin controls hippocampal spine synapse density and memory performance. Nat. Neurosci. 9, 381-388. doi: 10.1038/nn1656

Dogrukol-Ak, D., Tore, F., and Tuncel, N. (2004). Passage of VIP/PACAP/secretin family across the blood-brain barrier: therapeutic effects. Curr. Pharmaceut. Design 10, 1325-1340. doi: 10.2174/1381612043384934

Donahue, R. J., Venkataraman, A., Carroll, F. I., Meloni, E. G., and Carlezon, W. A. Jr. (2016). Pituitary Adenylate Cyclase-Activating Polypeptide Disrupts Motivation, Social Interaction, and Attention in Male Sprague Dawley Rats. Biol. Psychiatry 80, 955-964. doi: 10.1016/j.biopsych.2015.06.013

Dumais, K. M., and Veenema, A. H. (2016). Vasopressin and oxytocin receptor systems in the brain: sex differences and sex-specific regulation of social behavior. Front. Neuroendocrinol. 40:3. doi: 10.1016/j.yfrne.2015.04.003

Esch, B. E., and Carr, J. E. (2004). Secretin as a treatment for autism: a review of the evidence. J. Autism Dev. Disord. 34, 543-556. doi: 10.1007/s10803-004-2549-6

Firouzabadi, S. G., Kariminejad, R., Vameghi, R., Darvish, H., Ghaedi, H., Banihashemi, S., et al. (2017). Copy number variants in patients with autism and additional clinical features: report of VIPR2 duplication and a novel microduplication syndrome. Mol. Neurobiol. 54, 7019-7027. doi: 10.1007/ s12035-016-0202-y

Ghanizadeh, A. (2011). Ghrelin as a promising therapeutic target for co-occurring autism and epilepsy. Epilepsy Behav. 20, 420-421. doi: 10.1016/j.yebeh.2010.12. 009

Giladi, E., Hill, J. M., Dresner, E., Stack, C. M., and Gozes, I. (2007). Vasoactive intestinal peptide (VIP) regulates activity-dependent neuroprotective protein (ADNP) expression in vivo. J. Mol. Neurosci. 33, 278-283. doi: 10.1007/s12031007-9003-0

Guan, X. M., Yu, H., Palyha, O. C., McKee, K. K., Feighner, S. D., Sirinathsinghji, D. J., et al. (1997). Distribution of mRNA encoding the growth hormone secretagogue receptor in brain and peripheral tissues. Brain research. Mol. Brain Res. 48, 23-29. doi: 10.1016/s0169-328x(97)00071-5

Hashimoto, H., Shintani, N., Tanaka, K., Mori, W., Hirose, M., Matsuda, T., et al. (2001). Altered psychomotor behaviors in mice lacking pituitary adenylate 
cyclase-activating polypeptide (PACAP). Proc. Natl. Acad. Sci. U.S.A. 98, 1335513360.

Hill, J. M., Cuasay, K., and Abebe, D. T. (2007). Vasoactive intestinal peptide antagonist treatment during mouse embryogenesis impairs social behavior and cognitive function of adult male offspring. Exp. Neurol. 206, 101-113. doi: 10.1016/j.expneurol.2007.04.004

Hill, J. M., Mehnert, J., McCune, S. K., and Brenneman, D. E. (2002). Vasoactive intestinal peptide regulation of nerve growth factor in the embryonic mouse. Peptides 23, 1803-1808. doi: 10.1016/s0196-9781(02)00137-7

Hori, Y., Kageyama, H., Guan, J. L., Kohno, D., Yada, T., Takenoya, F., et al. (2008). Synaptic interaction between ghrelin- and ghrelin-containing neurons in the rat hypothalamus. Regul. Pept. 145, 122-127. doi: 10.1016/j.regpep.2007. 09.027

Horvath, K., Stefanatos, G., Sokolski, K. N., Wachtel, R., Nabors, L., and Tildon, J. T. (1998). Improved social and language skills after secretin administration in patients with autistic spectrum disorders. J. Assoc. Acad. Minor. Phys. 9, 9-15.

Hou, Z., Miao, Y., Gao, L., Pan, H., and Zhu, S. (2006). Ghrelin-containing neuron in cerebral cortex and hypothalamus linked with the DVC of brainstem in rat. Regul. Pept. 134, 126-131. doi: 10.1016/j.regpep.2006. 02.005

Iourov, I. Y., Vorsanova, S. G., Voinova, V. Y., and Yurov, Y. B. (2015). 3p22.1p21.31 microdeletion identifies CCK as Asperger syndrome candidate gene and shows the way for therapeutic strategies in chromosome imbalances. Mol. Cytogenet. 8:82. doi: 10.1186/s13039-015-0185-9

Jozwiak-Bebenista, M., Kowalczyk, E., and Nowak, J. Z. (2015). The cyclic AMP effects and neuroprotective activities of PACAP and VIP in cultured astrocytes and neurons exposed to oxygen-glucose deprivation. Pharmacol. Rep. 67, 332338. doi: 10.1016/j.pharep.2014.10.001

Katzman, M. A., Koszycki, D., and Bradwejn, J. (2004). Effects of CCK-tetrapeptide in patients with social phobia and obsessive-compulsive disorder. Depress. Anxiety 20, 51-58. doi: 10.1002/da.20012

Kawaguchi, Y., and Kondo, S. (2002). Parvalbumin, somatostatin and cholecystokinin as chemical markers for specific GABAergic interneuron types in the rat frontal cortex. J. Neurocytol. 31, 277-287.

Kingsbury, M. A., and Wilson, L. C. (2016). The Role of VIP in social behavior: neural hotspots for the modulation of affiliation, aggression, and parental care. Integr. Comp. Biol. 56, 1238-1249. doi: 10.1093/icb/icw122

Kojima, M., Hosoda, H., Date, Y., Nakazato, M., Matsuo, H., and Kangawa, K. (1999). Ghrelin is a growth-hormone-releasing acylated peptide from stomach. Nature 402, 656-660. doi: 10.1038/45230

Kojima, M., Hosoda, H., and Kangawa, K. (2001). Purification and distribution of ghrelin: the natural endogenous ligand for the growth hormone secretagogue receptor. Horm. Res. 56, 93-97. doi: 10.1159/000048143

Kojima, M., and Kangawa, K. (2005). Ghrelin: structure and function. Physiol. Rev. 85, 495-522. doi: 10.1152/physrev.00012.2004

Kolts, B. E., and McGuigan, J. E. (1977). Radioimmunoassay measurement of secretin half-life in man. Gastroenterology 72, 55-60. doi: 10.1016/s00165085(77) 80303-x

Konturek, S. J., Konturek, J. W., Pawlik, T., and Brzozowski, T. (2004). Brain-gut axis and its role in the control of food intake. J. Physiol. Pharmacol. 55, 137-154.

Koves, K., Kiss, G., Heinzlmann, A., Dochnal, R., Manczinger, M., Pal, A., et al. (2011). Secretin attenuates the hereditary repetitive hyperactive movements in a mouse model. J. Mol. Neurosci. 43, 109-114. doi: 10.1007/s12031-010-9408-z

Krishnaswami, S., McPheeters, M. L., and Veenstra-Vanderweele, J. (2011). A systematic review of secretin for children with autism spectrum disorders. Pediatrics 127, e1322-e1325. doi: 10.1542/peds.2011-0428

Lee, J., Lim, E., Kim, Y., Li, E., and Park, S. (2010). Ghrelin attenuates kainic acidinduced neuronal cell death in the mouse hippocampus. J. Endocrinol. 205, 263-270. doi: 10.1677/JOE-10-0040

Lehmann, M. L., Mustafa, T., Eiden, A. M., Herkenham, M., Eiden, L. E., and deficient, P. A. C. A. P. - (2013). mice show attenuated corticosterone secretion and fail to develop depressive behavior during chronic social defeat stress. Psychoneuroendocrinology 38, 702-715. doi: 10.1016/j.psyneuen.2012.09.006

Lemaire, M., Piot, O., Roques, B. P., Bohme, G. A., and Blanchard, J. C. (1992). Evidence for an endogenous cholecystokininergic balance in social memory. Neuroreport 3, 929-932. doi: 10.1097/00001756-199210000-00028
Levinson, D. F., Duan, J., Oh, S., Wang, K., Sanders, A. R., Shi, J., et al. (2011). Copy number variants in schizophrenia: confirmation of five previous findings and new evidence for 3q29 microdeletions and VIPR2 duplications. Am. $J$. Psychiatry 168, 302-316. doi: 10.1176/appi.ajp.2010.10060876

Li, Q., and Zhou, J. M. (2016). The microbiota-gut-brain axis and its potential therapeutic role in autism spectrum disorder. Neuroscience 324, 131-139. doi: 10.1016/j.neuroscience.2016.03.013

Lim, M. A., Stack, C. M., Cuasay, K., Stone, M. M., McFarlane, H. G., Waschek, J. A., et al. (2008). Regardless of genotype, offspring of VIP-deficient female mice exhibit developmental delays and deficits in social behavior. Int. J. Dev. Neurosci. 26, 423-434. doi: 10.1016/j.ijdevneu.2008.03.002

Lu, S., Guan, J. L., Wang, Q. P., Uehara, K., Yamada, S., Goto, N., et al. (2002). Immunocytochemical observation of ghrelin-containing neurons in the rat arcuate nucleus. Neurosci. Lett. 321, 157-160. doi: 10.1016/s0304-3940(01) 02544-7

Lyra, L., Rizzo, L. E., Sunahara, C. S., Pachito, D. V., Latorraca, C. O. C., Martimbianco, A. L. C., et al. (2017). What do Cochrane systematic reviews say about interventions for autism spectrum disorders? Sao Paulo Med. J. 135, 192-201. doi: 10.1590/1516-3180.2017.0058200317

Mak, S. O. K., Zhang, L., and Chow, B. K. C. (2019). In vivo actions of SCTR/AT1aR heteromer in controlling $\mathrm{Vp}$ expression and release via cFos/cAMP/CREB pathway in magnocellular neurons of PVN. FASEB J. 33, 5389-5398. doi: 10. 1096/fj.201801732RR

Malhotra, R. K., Wakade, T. D., and Wakade, A. R. (1988). Vasoactive intestinal polypeptide and muscarine mobilize intracellular $\mathrm{Ca} 2+$ through breakdown of phosphoinositides to induce catecholamine secretion. Role of IP3 in exocytosis. J. Biol. Chem. 263, 2123-2126.

Malone, R. P., Gratz, S. S., Delaney, M. A., and Hyman, S. B. (2005). Advances in drug treatments for children and adolescents with autism and other pervasive developmental disorders. CNS Drugs 19, 923-934. doi: 10.2165/00023210200519110-00003

Masuo, Y., Noguchi, J., Morita, S., and Matsumoto, Y. (1995). Effects of intracerebroventricular administration of pituitary adenylate cyclaseactivating polypeptide (PACAP) on the motor activity and reserpine-induced hypothermia in murines. Brain Res. 700, 219-226. doi: 10.1016/0006-8993(95) 00978-y

Moon, M., Kim, S., Hwang, L., and Park, S. (2009). Ghrelin regulates hippocampal neurogenesis in adult mice. Endocrine J. 56, 525-531. doi: 10.1507/endocrj. k09e-089

Neary, M. T., and Batterham, R. L. (2009). Gut hormones: implications for the treatment of obesity. Pharmacol. Ther. 124, 44-56. doi: 10.1016/j.pharmthera. 2009.06.005

Nelson, K. B., Grether, J. K., Croen, L. A., Dambrosia, J. M., Dickens, B. F., Jelliffe, L. L., et al. (2001). Neuropeptides and neurotrophins in neonatal blood of children with autism or mental retardation. Ann. Neurol. 49, 597-606. doi: 10.1002/ana. 1024

Nicot, A., Otto, T., Brabet, P., and Dicicco-Bloom, E. M. (2004). Altered social behavior in pituitary adenylate cyclase-activating polypeptide type I receptordeficient mice. J. Neurosci. 24, 8786-8795. doi: 10.1523/jneurosci.1910-04. 2004

Nijmeijer, J. S., Arias-Vásquez, A., Rommelse, N. N. J., Altink, M. E., Anney, R. J. L., Asherson, P., et al. (2010). Identifying Loci for the overlap between Attention-Deficit/Hyperactivity disorder and autism spectrum disorder using a genome-wide QTL Linkage Approach. J. Am. Acad. Child Adolesc. Psychiatry 49, 675-685. doi: 10.1016/j.jaac.2010.03.015

Nishijima, I., Yamagata, T., Spencer, C. M., Weeber, E. J., Alekseyenko, O., Sweatt, J. D., et al. (2006). Secretin receptor-deficient mice exhibit impaired synaptic plasticity and social behavior. Hum. Mol. Genet. 15, 3241-3250. doi: 10.1093/ $\mathrm{hmg} / \mathrm{ddl} 402$

Norrholm, S. D., Das, M., and Legradi, G. (2005). Behavioral effects of local microinfusion of pituitary adenylate cyclase activating polypeptide (PACAP) into the paraventricular nucleus of the hypothalamus (PVN). Regul. Pept. 128, 33-41. doi: 10.1016/j.regpep.2004.12.023

Ogata, K., Shintani, N., Hayata-Takano, A., Kamo, T., Higashi, S., Seiriki, K., et al. (2015). PACAP enhances axon outgrowth in cultured hippocampal neurons to a comparable extent as BDNF. PLoS One 10:e0120526. doi: 10.1371/journal.pone. 0120526 
Pang, Y. Y., Chen, X. Y., Xue, Y., Han, X. H., and Chen, L. (2015). Effects of secretin on neuronal activity and feeding behavior in central amygdala of rats. Peptides 66, 1-8. doi: 10.1016/j.peptides.2015.01.012

Pellegri, G., Magistretti, P. J., and Martin, J. L. (1998). VIP and PACAP potentiate the action of glutamate on BDNF expression in mouse cortical neurones. Eur. J. Neurosci. 10, 272-280. doi: 10.1046/j.1460-9568.1998.00052.x

Reichlin, S. (1988). Neuroendocrine significance of vasoactive intestinal polypeptide. Ann. N. Y. Acad. Sci. 527, 431-449. doi: 10.1111/j.17496632.1988.tb26998.x

Roman, C. W., Sloat, S. R., and Palmiter, R. D. (2017). A tale of two circuits: CCK(NTS) neuron stimulation controls appetite and induces opposing motivational states by projections to distinct brain regions. Neuroscience 358, 316-324. doi: 10.1016/j.neuroscience.2017.06.049

Rovira-Esteban, L., Peterfi, Z., Vikor, A., Mate, Z., Szabo, G., and Hajos, N. (2017). Morphological and physiological properties of CCK/CB1R-expressing interneurons in the basal amygdala. Brain Struct. Funct. 222, 3543-3565. doi: 10.1007/s00429-017-1417-z

Said, S. I., and Rattan, S. (2004). The multiple mediators of neurogenic smooth muscle relaxation. Trends Endocrinol. Metab. 15, 189-191. doi: 10.1016/j.tem. 2004.05.004

Seillier, A., Martinez, A. A., and Giuffrida, A. (2013). Phencyclidine-induced social withdrawal results from deficient stimulation of cannabinoid $\mathrm{CB}(1)$ receptors: implications for schizophrenia. Neuropsychopharmacology 38, 1816-1824. doi: 10.1038/npp.2013.81

Shen, C. J., Zheng, D., Li, K. X., Yang, J. M., Pan, H. Q., Yu, X. D., et al. (2019). Cannabinoid $\mathrm{CB} 1$ receptors in the amygdalar cholecystokinin glutamatergic afferents to nucleus accumbens modulate depressive-like behavior. Nat. Med. 25, 337-349. doi: 10.1038/s41591-018-0299-9

Small, C. J., and Bloom, S. R. (2004). Gut hormones and the control of appetite. TEM 15, 259-263.

Stabler, C. L., Li, Y., Stewart, J. M., and Keselowsky, B. G. (2019). Engineering immunomodulatory biomaterials for type 1 diabetes. Nat. Rev. Mater. 4, 429450. doi: 10.1038/s41578-019-0112-5

Stack, C. M., Lim, M. A., Cuasay, K., Stone, M. M., Seibert, K. M., Spivak-Pohis, I., et al. (2008). Deficits in social behavior and reversal learning are more prevalent in male offspring of VIP deficient female mice. Exp. Neurol. 211, 67-84. doi: 10.1016/j.expneurol.2008.01.003

Starr, E. R., and Margiotta, J. F. (2017). Pituitary adenylate cyclase activating polypeptide induces long-term, transcription-dependent plasticity and remodeling at autonomic synapses. Mol. Cell. Neurosci. 85, 170-182. doi: $10.1016 /$ j.mcn.2017.10.002

Takashima, A., Maeda, Y., and Itoh, S. (1993a). Influence of chronic intracerebroventricular infusion of vasoactive intestinal peptide (VIP) on memory processes in Morris water pool test in the rat. Peptides 14, 1073-1078. doi: 10.1016/0196-9781(93)90089-y

Takashima, A., Maeda, Y., and Itoh, S. (1993b). Vasoactive intestinal peptide (VIP) causes memory impairment in passive avoidance responding of the rat. Peptides 14, 1067-1071. doi: 10.1016/0196-9781(93)90088-x

Takayanagi, Y., Yoshida, M., Takashima, A., Takanami, K., Yoshida, S., Nishimori, K., et al. (2017). Activation of supraoptic oxytocin neurons by secretin facilitates social recognition. Biol. Psychiatry 81, 243-251. doi: 10.1016/j.biopsych.2015. 11.021
Tick, B., Bolton, P., Happe, F., Rutter, M., and Rijsdijk, F. (2016). Heritability of autism spectrum disorders: a meta-analysis of twin studies. J. Child Psychol. Psychiatry Allied Discipl. 57, 585-595. doi: 10.1111/jcpp.12499

Troke, R. C., Tan, T. M., and Bloom, S. R. (2014). The future role of gut hormones in the treatment of obesity. Ther. Adv. Chronic. Dis. 5, 4-14. doi: 10.1177/ 2040622313506730

Vargish, G. A., Pelkey, K. A., Yuan, X., Chittajallu, R., Collins, D., Fang, C., et al. (2017). Persistent inhibitory circuit defects and disrupted social behaviour following in utero exogenous cannabinoid exposure. Mol. Psychiatry 22, 56-67. doi: $10.1038 / \mathrm{mp} .2016 .17$

Wang, L., Zhang, L., and Chow, B. K. C. (2017). Secretin modulates the postnatal development of mouse cerebellar cortex via PKA- and ERK-dependent pathways. Front. Cell. Neurosci. 11:382. doi: 10.3389/fncel.2017.00382

Wang, R., Chow, B. K. C., and Zhang, L. (2019). Distribution and Functional Implication of Secretin in Multiple Brain Regions. J. Mol. Neurosci. 68, 485-493. doi: 10.1007/s12031-018-1089-z

Whissell, P. D., Bang, J. Y., Khan, I., Xie, Y. F., Parfitt, G. M., Grenon, M., et al. (2019). Selective activation of cholecystokinin-expressing GABA (CCK-GABA) neurons enhances memory and cognition. eNeuro 6:ENEURO.0360-18.2019. doi: 10.1523/ENEURO.0360-18.2019

Wren, A. M., and Bloom, S. R. (2007). Gut hormones and appetite control. Gastroenterology 132, 2116-2130. doi: 10.1053/j.gastro.2007.03.048

Yamagata, T., Urano, H., Weeber, E. J., Nelson, D. L., and Nishijima, I. (2008). Impaired hippocampal synaptic function in secretin deficient mice. Neuroscience 154, 1417-1422. doi: 10.1016/j.neuroscience.2008. 04.037

Yamashita, Y., Makinodan, M., Toritsuka, M., Yamauchi, T., Ikawa, D., Kimoto, S., et al. (2019). Anti-inflammatory effect of ghrelin in lymphoblastoid cell lines from children with autism spectrum disorder. Front. Psychiatry 10:152. doi: $10.3389 /$ fpsyt.2019.00152

Yuan, Y., Lee, L. T., Ng, S. S., and Chow, B. K. (2011). Extragastrointestinal functions and transcriptional regulation of secretin and secretin receptors. Ann. N. Y. Acad. Sci. 1220, 23-33. doi: 10.1111/j.1749-6632.2011.05987.x

Yung, W. H., Leung, P. S., Ng, S. S., Zhang, J., Chan, S. C., and Chow, B. K. (2001). Secretin facilitates GABA transmission in the cerebellum. J. Neurosci. 21, 7063-7068. doi: 10.1523/jneurosci.21-18-07063.2001

Zhang, L., and Chow, B. K. (2014). The central mechanisms of secretin in regulating multiple behaviors. Front. Endocrinol. 5:77. doi: 10.3389/fendo.2014.00077

Zhang, W., Lin, T. R., Hu, Y., Fan, Y., Zhao, L., Stuenkel, E. L., et al. (2004). Ghrelin stimulates neurogenesis in the dorsal motor nucleus of the vagus. J. Physiol. 559, 729-737. doi: 10.1113/jphysiol.2004.064121

Conflict of Interest: The authors declare that the research was conducted in the absence of any commercial or financial relationships that could be construed as a potential conflict of interest.

Copyright (c) 2020 Qi and Zhang. This is an open-access article distributed under the terms of the Creative Commons Attribution License (CC BY). The use, distribution or reproduction in other forums is permitted, provided the original author(s) and the copyright owner(s) are credited and that the original publication in this journal is cited, in accordance with accepted academic practice. No use, distribution or reproduction is permitted which does not comply with these terms. 